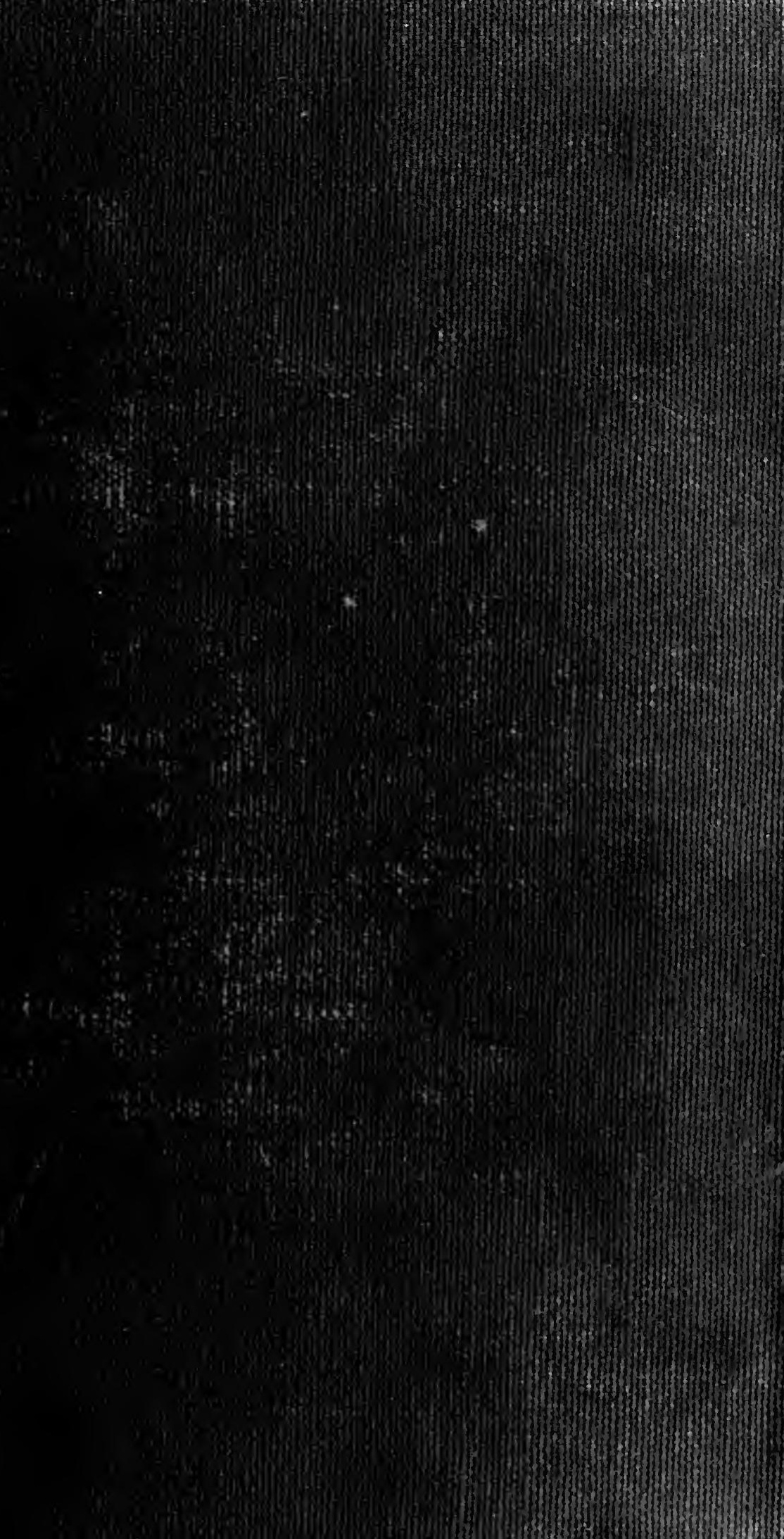




\section{EXCFANGE}

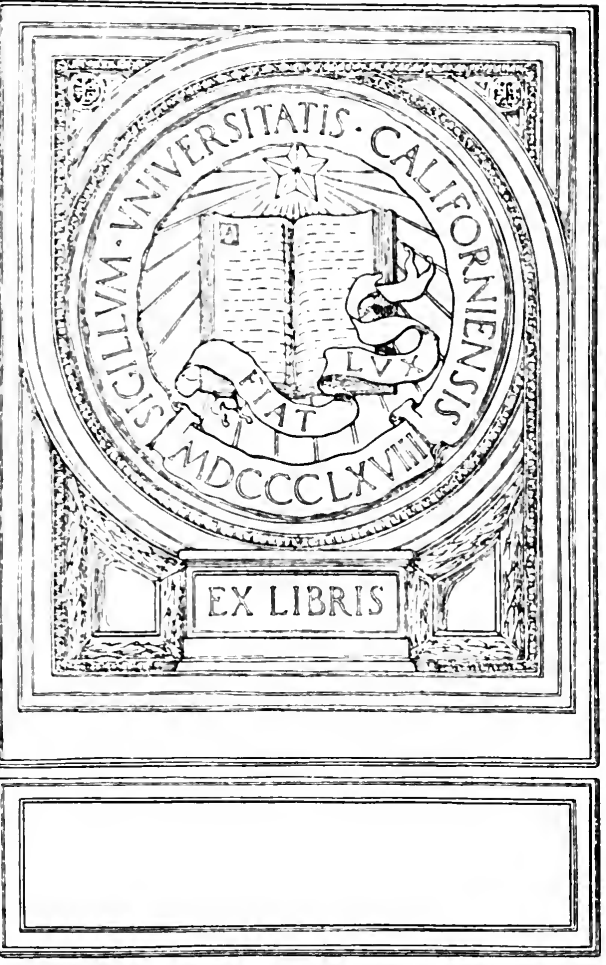




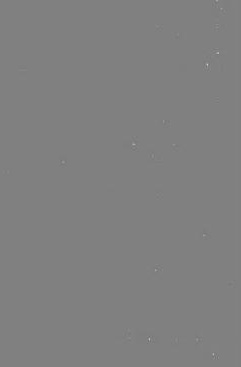

$\therefore$

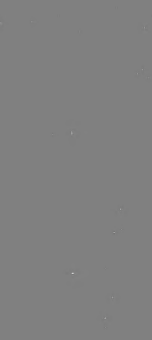

$\infty$ 
Digitized by the Internet Archive in 2007 with funding from Microsoft Corporation 



\section{PUBLICATIONS}

OF THE

\section{CLARK UNIVERSITY LIBRARY}

WORCESTER, MASS.

EDIted Ry LOUIS N. WILSON, LITT. D., LIBRARIAN

Vol. 6

OCTOBER, 1922.

No. 6

\section{A Graduate School \\ of}

Geography

By

William M. Davis, ScD., Ph.D.

Commencement Address

at

Clark University, June 12, 1922

Clark Hniurraity Mibrary

Morrester. ERasa. 



\section{A Graduate School of \\ Geography}

By

William M. Davis, ScD., Ph.D.

Commencement Address

at

Clark University, June 12, 1922

Clark Mniurrsity Tithrary

marreater. eflass. 


\section{FOREWORD}

During the last few years, there has been a remarkable awakening in America of a keen and sympathetic interest in the affairs of the world.

This interest calls for a greater knowledge of foreign lands, of the various peoples inhabiting the world, of the natural resources, of the climatic conditions, and the influence of different climates upon the several races of men. In other words, it means that we demand a fuller and more accurate knowledge of geography.

With this awakening in America of a greater interest in geography, it seemed to be most appropriate that this country should hear from the dean of American geographers as to what his ideal would be for the promotion of this field of study in American universities. The accompanying address was delivered to an audience of about twelve hundred people; but it is our desire that it may be read by a much larger number, that it may reach all those who are especially interested in this field of study and that they may retain these words from Professor Davis in their private libraries. For this reason we have arranged for the publication and distribution of this address. We feel certain it will inspire all in the geographical profession to higher ideals and greater activity, and we also trust that it may convince many with administrative responsibility of the greater significance of geographical research and education in this country.

Wallace W. Atwood. 


\title{
A Graduate School of Geography
}

\author{
By William M. Davis, Sc.D., Ph.D.
}

\section{A CASTLE IN THE AIR}

In spite of a wide-spread prejudice against building castles in the air, I propose this afternoon to consider a construction of that kind; for if castles are not to be built in the air, where in the world are they to be built: surely not underground or in the water! All the castles I have ever seen were built in the air; their foundations were in the ground, of course, but the castles themselves were in the air. My proposal therefore needs no defence.

In view of the good number of castles already built, some of them very high in the air, even on mountain tops, for occupation by the defendants of various sciences, it is gratifying to learn that plans are advancing for the erection here in Worcester of a castle of the particular kind in which my own interest is most excited, a geographical castle. But it is, on the other hand, regrettable to find that the proposal to erect a castle, a stronghold, dedicated to geography alone seems, even in intellectual circles, to need explanation if not justification; so little is the vast and varied content of geography understood, so imperfectly is the great opportunity for original research in geography appreciated, so halting is the recognition of the importance that the results of such research will have in the conservation and consecration of the wide spaces of the earth to the better advantage of mankind. Let us try to rise to a realization of the geographical opportunity before us.

\section{THE EPOCH OF GEOGRAPHICAL DESCRIPTION}

We must remember that the geographical epoch, in which the first discovery of the general outline of the lands and waters over the world was made, is now closed. The work that remains for the coming geographical epoch is not the discovery but the description of the earth's features; and their description can be properly prepared only by pro- 
fessional geographers, unlike in disposition and training to the bold pathfinders who made the first entry into remote and unknown regions. Moreover, the labor involved in the future preparation of such descriptions will be enormously greater than that already expended in the epoch of discovery. I fear that few persons have any idea of how much geographical work remains to be done or of the amount of labor demanded in doing it. Let me tell you that even most of our own states, for example, Tennessee or Montana, familiar by name to all of us and well known locally in an empirical way to many of their inhabitants, have not yet been described with professional thoroughness. There are absolutely no treatises, not even handbooks in which the regional geography of most of our states is set forth in a thoroughly competent and comprehensive manner. How vastly ignorant then must we be of South America, Africa and Asia! The geography of the world is really yet to be written, and in preparation for that writing the world must be explored all over again, not by mere travelers, but by geographical experts. In order to earry on the re-exploration of the world and give adequate opportunity for the preparation of the many scholarly volumes in which a competent description of the re-explored world shall be contained, many institutions in all parts of the world must cooperate; and one of those institutions should be the geographical stronghold which we hope to see ereeted here.

\section{THE ESSENTIAL OBJECTS OF A GEOGRAPHICAL STRONGHOLD}

What is the essential object of such a stronghold? In the first place, the object of a geographical stronghold may be most advantageously reached if it is built up over a well planned lower story in which introductory collegiate instruction shall be offered in geography and other undergraduate subjects; but in the stronghold itself the object should be primarily geographical research and only secondarily geographical teaching. Let me at once make clear and insist upon this main reason for the construction of a geographical stronghold. It should not be planned primarily to provide either introductory or utilitarian instruction, although such instruction should not be altogether excluded from it. The 
main reason for the construction and maintenance of the stronghold should be to add geographical contributions to the sum of human knowledge, without regard to what is called their practical value. Immediate usefulness, direct application of the knowledge gained should not be made a prime requisite in an institution of research; and particularly not in a geographical stronghold, because the higher branches of geography are as yet so little developed. The essential tasks of a gographical stronghold will therefore not be the imparting of geographical knowledge so that it may be imparted again elsewhere as in teaching; or so that it may be applied elsewhere as in geographical engineering-I will explain later what geographical engineering is. If the work be mainly of that utilitarian nature, the stronghold will be, from the point of view which I wish to insist upon, largely a failure.

The first duty of a geographical stronghold -or, to use its proper name, of a Graduate School of Geography-must be geographical research; and until such research has advanced well beyond its present limits the acquisition and not the dissemination of geographical knowledge must be the main object in view: the dissemination of the acquired knowledge will follow as a secondary duty. It may be well urged for many years to come that, even in the case of graduate students, the best way to prepare them for the higher reaches of geographical science will not be to impart to them the geographical knowledge already gained; teaching of that kind is properly the task of a college. The correspondingly proper task of a professional graduate school is the cultivation of proficiency in the pursuit of new knowledge; and such proficiency is best aequired not by direct instruction in formal lecture courses, but by placing those who wish to acquire it in close association with others who, already proficient, are using their proficiency in research.

RESEARCH THE BEST PREPARATION FOR HIGH-GRADE PRACTICAL, WORK

Geography is not peculiar in that respect. I have it on good authority that even in chemistry, a science of enormous practical importance, the best training for a chemical engineer is, 
not alone the study of those chemical processes which are already known to have practical value, but the investigation of new processes without regard to their application; and this for the good reason that the essential thing for the really proficient chemical engineer is not simply to know this or that treatment of a problem which has already been solved, but to know how best to attack and solve new problems. Knowledge of that sort comes best by attacking and trying to solve new problems, under the guidance of experts who are themselves chiefly engaged in solving new problems. So with the development of a really proficient geographer. It will not be enough to teach him a certain share of what is already known about geography ; he must also learn how to find out more than is already known; and the very best way for him to do that is to spend a few years in an institution primarily devoted to geographical research.

\section{A STAFF OF NINE PROFESSORS OF GEOGRAPHY}

Of what should such an institution consist? I have thus far described it as a castle, a stronghold; but I hardly need say that the most important elements of such a stronghold are not walls but men; geographers. They must of course have rooms to work in; and I hope that the Graduate School of Geography in Clark University will eventually occupy a large building, planned for and devoted to research; but the essential thing is the men. A strong staff of full professorial rank will be needed. There should be at least one professor for each grand division or continent, hence five in all; it would be much better to have two for each of the less known continents, South America, Africa and Asia, or eight professors in all; and another should be added for Australasia, Polynesia and the oceans, thus making nine in all. Those nine geographers, or five if nine cannot be secured, would constitute the central and permanent staff of the institution. There should be a good number of others temporarily or peripherally attached, as I will explain later: and all of these should be in addition to and independent of the geographical staff for undergraduate instruction in the college. 
If you suggest that one or two geographers for a continent is a lavish provision, I must insist that it is a small provision. For each geographer must be responsible for the regional description of a large area, and that means that he must know the form of its surface, its climate, its more important vegetable and animal occupants, its human inhabitants, its political subdivisions, its products and industries, and its transportation and trade. And all these subjects must be known, not as made up of isolated items unrelated to each other, but as correlated items all in their natural and interdependent juxtaposition, thus constituting the landscapes and manifesting the activities of the region. To know so much as that about a continent is no small responsibility. But in addition to this continental responsibility in regional geography, each member of the staff should be a specialist in the subject of one of the eight larger systematic divisions of geography-land and water forms, climate, plant geography, animal geography, human geography, economic geography, historical geography, and history of geography. The difference between the regional and the systematic aspects of geography is this: In each division or special subject of systematic geography such as land and water forms, climate, and the rest, all the classes of facts treated under that subject should be studied in whaiever part of the world their examples are found; while in each large division of regional geography, such as North America or Africa, all kinds of facts to whatever special subject of sytematic geography they belong must be studied in their natural associations. Surely when the work to be done in a geographical stronghold is thus envisaged a permanent staff of nine men will not seem too large.

\section{REGIONAL GEOGRAPHY THE CULMINATION OF GEOGRAPHICAL}

\section{SCIENCE}

Let me make it clear why I lay so much emphasis on regional geography, in contrast to systematic geography. However important the different divisions of systematic geography are, they yield only a discontinuous sort of knowledge. Under land forms we may study about volcanoes, and learn as much as possible about all of them, wherever they are; but the items 
of knowledge that we thus gain compel us to leap about all over the world in order to locate them. Similarly, we may learn under human geography all about fishing villages, wherever situated; but there again we must leap about to locate the items that we learn. On the other hand the study of regional geography gives us a continuous or areal sort of knowledge; if we study the regional geography of Japan, for example, we shall learn not only the distribution of its many volcanoes and of its many fishing villages, but of all its other geographical features; and it is this continuous or areal knowledge that is usually and properly implied when we speak of geography in a general way. The study of the various divisions of systematic geography has, indeed, its chief value as a preparation for the study of regional geography; hence no one should consider himself a geographer, until he has become expert in the regional geography of at least one large area, preferably as large as a continent. Moreover, not until such expertness is gained is a geographer's knowledge likely to be of practcal application in such a profession as geographical engineering. A thorough representation of regional geography is therefore essential in a well developed Graduate School of Geography.

\section{RESEARCH BY EXPLORATION}

How will these nine geographers do their work? First and foremost, each one of them will be expected to take part from time to time in the actual exploration of the continent for which he is responsible, or in the investigation of his special subject in systematic geography; and between times he must make himself acquainted with the work of other explor. ers of his continent, and of other investigators in his special systematic subject. His own exploratory work, in which he should be accompanied by one or more advanced students, will require absence from Worcester for periods of half a year or a year every three, four or five years; and the digestion and publication of the results of his exploration will require, after he returns home, at least twice as much time as he spent in the field. The rest of his time at home should be given to the study of explorations and investigations by others, so that each 
one of the nine professors shall become a recognized center of absorption and radiation of regional and special knowledge. On this plan, two professors would ordinarily be absent every year; three or four others would be engrossed in preparing for publication the material they secured in the field during their absence one or two years before; and each of the remaining three or four professors would be very busy in reviewing and assimilating the work of other geographers in various parts of the world, as far as it referred to matters for which he is responsible. If, under these conditions, any professor finds that he has some free time left over, he might give it to the preparation and delivery of set courses of lectures.

\section{CURATORS AND MATERIAL EQUIPMENT}

You may have noticed, that, apart from the staff of nine professors, nothing has yet been said about the rest of the School's establishment. While I still maintain that the essential feature of the School must be its corps of research professors, there are also other features of equipment which the professors will say are essential, even if I do not.

There must be in the first place a comprehensive library of geography and allied subjects in charge of a scholarly librarian; not simply a man who will put books back in their places on the shelves, but a man well versed in geographical literature, an active collaborator with the professors in keeping the library up to date in all its departments, and perhaps having so great an interest in geographical production as to serve as editor of the School's publications. There must be, in the second place, a complete collection of modern, large-scale topograpical and hydrographical maps of all countries which publish such maps, and this collection should be in charge of a cartographer; not a mere draftsman, but an experienced craftsman with a real understanding of the outdoor things that maps represent and a dextrous hand for the construction of such new maps as are needed in the School work; instruction in so much of surveying and map making as young geographers need might be given by this member of the staff. In the third place there should be a large and growing collection of models, in charge of a trained and skilful model-maker; 
not a mere artificer but a geographer of artistic capacity and outdoor experience, competent to design and construct truthfully expressive models himself. There should be, in the fourth place, an extensive and ever-growing collection of geographical photographs, not in charge of a mere photographer, but of a geographer competent to make scientific selection of characteristic views for the illustration of geographical subjects and regions. And in the fifth place there should be a comprehensive collection of the products of all countries in charge of an experienced economic geographer, unless the School proposes to depend for such material on the great Commercial Museum in Philadelphia. The material equipment of a graduate school of geography is therefore a somewhat formidable matter. It must be vigorously looked after.

\section{A CENTRAL BUREAU FOR GEOGRAPHICAL ILLUSTRATIONS}

Let me say a few words more about the collections of geographical photographs and models, in order to explain the manner in which such collections may be made useful not only in Clark University, but all over the country wherever geography has recognition. Every college where geography is taught needs a collection of lantern slides for the illustration of its lectures. At present each professor of geography in all those colleges has to build up his own collection as best he can; as a result such collections are very uneven and imperfect. There is no central bureau where well selected sets of lantern slides for the illustration of special subjects or of special regions can be obtained. What a boon it would be for professors of geography in every part of the United States if the Graduate School of Geography at Clark University would undertake to form a standard collection of photographs and lantern slides; not a finished collection, but a constantly growing collection, from which one could order, for example, an elementary set of 10 slides or an advanced set of 50 slides for the illustration of the physical geography of coasts; or an elementary set of 15 slides or an advanced set of 100 slides for the illustration of the regional geography of Colorado. A great amount of correspondence and travel, of reading and study would be required before such a collection was well 
developed: but when it came to be known that the sets made up from the collection were composed of pictures critically selected by a competent geographer, so that they would really accomplish their purpose, all geographical eyes would be often turned to Clark.

\section{A SERIES OF GEOGRAPHICAL MODELS}

A similarly beneficent work could be done by establishing a standard collection of geographical models, from which duplicates could be had at the cost of casting and coloring, without charge for the making. Like the lantern slides, these might illustrate both systematic and regional subjects. Thus, there might be a set of five models to exhibit the successive changes of a volcanic mountain from its youth of eruptive construction to its old age of erosional degradation, and so on for other physical features. Similarly there might be models representing certain striking features of different countries: these, on account of their expense, would be less often sold to colleges than to museums where they would attract much attention; but the systematic series would surely become popular as well as serviceable in the geographical laboratories of colleges; for such models may serve not only in illustration of type forms, but also as the basis for very disciplinary exercises in landscape description, a phase of geographical instruction which is too generally neglected. Such instruction may be advisedly begun in field excursions, where it can be grounded on the direct observation of nature; but the variety of landscape on which advantageous exercise may be had will be greatly extended if field excursions are supplemented by models. But I must turn away from this attractive topic, and consider again the Graduate School itself.

\section{AN ENCOURAGING ANALOGY FROM ASTRONOMY}

If we now return to consider the work of the research professors, perhaps you will ask: Is it really worth while to study the world in so much detail as has been thus far implied. Let me answer that question by a celestial analogy. The astronomical observatory maintained on Mt. Wilson in southern California by the Carnegie Institution of Washington- 
this being a shining example of one of those lofty mountaintop castles already alluded to-has a corps of high-grade astronomers devoting all their time and abilities to the study of the sun and the stars. They have nothing whatever to do with teaching. They never stop to ask whether their discoveries will have practical application or not. But first informing themselves thoroughly in all branches of astronomy, as well as in the allied sciences of mathematies and physies, they perseveringly catalogue and chart the stars, large and small, as so many facts of occurrence; they measure their brightness with the photometer and they analyze their composition with the spectroscope; and, marvellous to say, by combining spectrum and brightness they determine the distance of stars that are so immensely far away that they have no measurable parallax! They give the most ingenious and penetrating study to the distribution and movement of stars in space. They determine with great accuracy the periods of. revolution of what are known as spectroscopic doubles, the two components of which cannot be separated even by the most powerful telescopes. Can you conceive of anything more utterly useless? And yet the world applauds their work.

The spirit of devotion to research which characterizes the staff of an astronomical observatory is the spirit which should dominate and guide the staff of a Graduate School of Geography. For if it be praiseworthy to spend years, without the least regard to what is vainly called " utility," on the construction of catalogues and classifications of stars, most of which are invisible to the naked eye and inconceivably distant from our solar system, shall it not be praiseworthy also to spend years in the study of every geographical feature in every part of the world, without the least regard to whether the study leads to utility or not? The facts of one science are of the heavens, heavenly; those of the other are of the earth, earthy. But who shall say that a ninth magnitude star in such and such a part of the sky is a more worthy object of study than a ridge or a ravine in such and such a part of the earth? The star may be very large, but it is far away; the ridge or the ravine may be very small, but it is near at hand. The study of the earth, our own earth, is surely deserving of all the time and 
skill we can give to it. And even if, among various other geographical strongholds, the one here to be established eventually gains its quota of nine professors of geography, there will be abundant work for them all to do for years and years to come. Indeed, it is highly probable that, what with the evergrowing demands of science, the scope of the work to be done in geography will be expanded about as fast as the advance of the work goes on.

\section{THE STANDARDIZATION OF GEOGRAPHY}

But even as geography is now conceived, do not imagine that the staff of nine professors will find their progress to be all clear sailing, as if their course were already charted and their duties specified. That is by no means the case. One of the most important parts of their work will be its standardization, both as to content and as to method, concerning which many problematic matters, now unsolved or imperfectly solved, must be carried to a conclusion. Let us examine first those touching the content of geography.

How shall the description of land forms be treated so as to distinguish that special division of geography from its relative in geology? How much physical meteorology shall be included in climatology? What facts concerning the plants and animals of a region shall be treated in a truly geographical essay, so that it shall not duplicate sections of botanical and geological essays? How shall the essential factors of economic and of historical geography be treated so that they shall have a quality of their own, and not be merely selections from economics and history? All these questions must be examined and answered before the geographer can assure himself that all phases of geography, systematic as well as regional, are not merely restatements of parts of other subjects. He must see to it that all his own statements are essentially geographical, and of a kind that other subjects do not duplicate. Not that the establishment of sharp limits between the contents of neighboring sciences is desirable, nor that trespassing upon a neighboring science is in itself undesirable; but that when a geographer has so serious a responsibility placed upon him as the regional description of a large area of the earth's sur- 
face, he is more likely to meet it if he does not dissipate his time and energy and thought upon subjects for which he is not responsible.

While I am speaking of this matter, let me add that a geographer should resent the implication made by those who argue that the interest or importance of certain nongeographical matters is reason enough for their introduction into geographical essays. To accept that argument is a confession that the truly geographical elements in geographical essays are of so little importance and interest that such essays need the stimulation of irrelevant matters. That is not true. Geography needs no padding, no seasoning by items and scraps of other subjects. It is, like them, sufficient unto itself. Did you ever hear of an astronomer or a geometer or a physicist or a botanist who thought that his science needed to be spiced up by any other in order to attract attention? Never! All kinds of subjects must be studied, and studied for themselves in this studious world; and geography is one of them. Let geography therefore be pursued as earnestly, as devotedly, as wholeheartedly and as single-mindedly as any other subject; and let it accept cheerfully and contentedly the place that it can win on its own merits in the constellation of the sciences.

\section{THE LIMITS OF GEOGRAPHY}

It is, however, certainly a curious thing that geography still needs the development and definition of its content in the manner that I have just intimated. One might almost call it a moron among the sciences, for although it is very old in years it has not yet come into the full possession of its senses. It is a part of the duty of trained professional geographers to arouse and awaken their science, both by defining and by limiting its content, especially in its regional aspect, which is the culmination of geography. The solution of this task is largely a question of the point of view; and the essential point of view for a geographer is one from which he can clearly see the actual constitution of a region as it exists in the " today" of human history. Let it be remembered that, as already noted, the geography of a region of the earth must include its 
land and water forms, its climate, its more significant plants and animals, its human inhabitants, its political divisions, its products and industries, and its trade and transportation; and that all these elements must be conceived in their actual spacial relations, as they exist together and interact upon one another. Regional geography is therefore an immensely complex subject, even if all non-geographical elements are excluded from it; all the more wisely therefore should a geographer hold only to truly geographical elements, as above intimated.

Indeed, even when properly limited, regional geography is so complex that some critics assert it cannot be successfully mastered and treated by one man. There is no question that it cannot successfully be treated by a geographically uninformed, untrained, undisciplined man; or by a trained man who gives part of his attention to other sciences; and it may perhaps be true that it cannot be so well treated by one informed, trained and disciplined geographer working alone as by several informed, trained and disciplined geographers, each responsible for a part of the total subject and all working together in a team. No decision need be made on that question now, because the problem has never been given study long enough and serious enough to answer it. My own belief, however, is that such a staff of professional geographers as I have indicated will, after a score of years or more, reach such a measure of success in their tasks as to show that one-man regional descriptions are of great value. But if that belief be wrong, and if one-man geography be insufficient, the remedy is simple enough; geographical exploration must then be done by pairs of geographers, or trios, or quartettes, or groups working together, each member supplementing the work of his associates. Whatever the decision is on this point matters very little today; the essential thing is that the work must be done, and done in the best way possible. So much then for the content of geography. Now for its methods.

THE ART OF GEOGRAPHICAL DESCRIPTION

The staff of a Graduate School of Geography will have to take their share not only in defining and cultivating a scien- 
tific method of geographical investigation; they must also develop an artful method of geographical description. While a geographer is in the field, the subject of his investigation and his method of attacking it will occupy his mind. When he returns home the statement of his results in form for their communication to others will occupy his mind. In both occasions his mind will be fully occupied, however great his capacity. The science of investigation is somewhat technical; I cannot discuss it here; but the art of presentation may be briefly considered. Many results of exploration may be best presented on maps; some results may be presented in photographs, sketches and diagrams; some in models and some in statistical tables; but the great body of results is best presented in words. Now, while the geographical facts coexist simultaneously in their regions, they cannot be presented simultaneously in a report upon a region; a written report must present them consecutively, word after word, line after line, page after page. It may surprise you to learn, but I believe it to be true, that the future staff of geographers in the Clark Graduate School of Geography will have a very serious problem to solve before they can establish, even in general terms, a standard method of presenting or reporting upon the results of their explorations.

By such a standard method $I$ do not mean anything rigid and inflexible; but a method that will give the reader of a report a true and vivid concept of the region described. For just as accuracy is the essential object in the science of investigation, so intelligibility is the essential object in the art of presentation, and one of these high qualities is about as diffcult of acquisition as the other. It is unfortunately true that certain leading geographers are stronger in the possession of their science within themselves than in its presentation to others. It would almost seem, from their preference for possession and their indifference to the fine art of presentation, that they hold possession to be in geography, as it is in the law, nine points of the whole ten; but that is an unscholarly attitude. Of what avail is knowledge if it is not clearly set forth; of what value is an obscure presentation in which at least a part of the truth is lost. I trust that no professor or 
student of geography in Clark University will be indifferent in this matter; for accuracy in investigation and intelligibility in presentation are correlated essentials, and hence lack of intelligibility in presentation is too often an accompaniment of a sort of carelessness that is incompatible with accuracy in investigation.

ERRORS TO BE AVOIDED

How is the art of geographical presentation to be acquired and communicated? Perhaps you may imagine that articles and reports of standard excellence in the presentation of problems in regional geography already abound, and that all that is needed is to adopt and copy their method; but such is by no means the case. In the first place a large number of articles and books commonly classed as igeographical are chiefly narratives in which the narrator, often an untrained traveler, gives a leading position to his personal experiences, although they are very subjective matters. Narrative presentation is certainly entertaining to the general reader, and it is not to be dispensed with ; but it falls far short of satisfying the objective demands of scientific geography, just as the narrative of a plant collector would fall short of the demands of scientific botany.

In the second place many geographical articles and reports, although they are presented in a descriptive instead of in a narrative form, nevertheless treat problems of less extent than those of full-fledged regional geography; they are useful contributions to geographical science, but they fail to reach a complete regional treatment. In the third place, many articles that are in part regional are also in part analytical, in that they attempt to demonstrate an explanation for some fact or phenomenon that they describe; indeed, such articles are often largely geological, in that they turn attention away from the facts of today and direct it to the past conditions and processes by which the present-day facts have been brought about. Articles of this kind are indispensable to progress, but their analytical discussions should be completed before regional description is begun; their results should be standardized and systematized before they can be properly used in regional description; and when the results are em- 
ployed in their standardized and systematized form, the analysis upon which the standardization and systematization are based should not be repeated. Explanatory description in a regional essay should be used without any analytical demonstration.

\section{THE DIFFICULTY OF REGIONAL DESCRIPTION}

Finally, when regional description is attempted, it is too often inexpert in that it fails in the prime object of such description; namely, to give a vivid account of all the geographical elements of a region in their natural and interde. pendent combinations. Some such articles are faulty in a way that shows clearly enough how undeveloped the art of geographical presentation still is; for they leave their readers to work out, by the aid of such maps as they may possess, various details of location, which the author himself ought to have made clear once for all, by map, diagram or otherwise. Many other such articles are faulty in attempting to define the location of physical features or boundaries in terms of the location of small towns or villages, the names of which are not only unknown to most readers, but undiscoverable even in good atlases! Very few such articles present at the outset a simple account of the whole region and of its subdivisions in such manner that, whenever any local feature is later mentioned, it may be at once and very easily located in terms of the introductory account; and as a result geographical descriptions are often so obscure and difficult to follow that even geographers turn aside from them, discouraged. It is as if the investigator felt indifferent to the labor that his readers must undergo while reading his report, before they can learn what he has done, without realizing that such indifference costs him a loss of influence.

\section{GEOGRAPHERS AND TRAVELERS}

One of the reasons for these various deficiencies in the present status of geography deserves explicit mention: it is that the authors of articles published in the geographical periodicals of the leading geographical societies of the world are in a regrettable number of instances, not trained and dis- 
ciplined geographers, but simply intelligent and observant travelers. It would seem that such persons, on visiting and returning from a little traveled region, were thereupon popularly classed as geographers, whatever they were before their travels began; and this idea is given support by the character of the membership of many geographical societies, because such membership is made up largely of generouslyminded persons who, whether they have traveled or not, are glad to support the work of the societies in which they are enrolled. That they should do so is most gratifying, but that they should be regarded as geographers because of so doing is disappointing.

To return to astronomy for an illustration, do you suppose that the Astronomical Society of America is made up of intelligent persons who like to look at the nocturnal sky and recognize the constellations, and of persons who, whether they like to look at the sky or not, have pleasure in contributing to the cost of publishing an astronomical journal? Not at all : that society is made up of qualified astronomers; no others need apply. But so far as I know only one of the many geographical societies in the world limits its members to geographers; and, although its requirements for membership are not severe, and although diligent search has been made to discover as many qualified members as possible, that society has not yet succeeded in discovering 200 persons fit to be members in its country of over $100,000,000$ population.

Whatever the cause of the characteristic imperfections in regional presentation today, it is manifest that improvements can be made only by persistent conscious effort. A large share of the attention of research professors in a Graduate School of Geography must be directed to making that effort successful.

\section{MEANS AND MEN}

It is an easy matter to outline the constitution of a Graduate School of Geography, as I have just done. It is a more difficult matter to establish such a school. Obstacles of two kinds stand in the way. Those of one kind are merely difficulties; those of the other kind are more serious, they are dangers. The difficulties are only those of finding means 
and men. Difficulties of that kind can be overcome in time if they are attacked energetically and persistently. Whether the means or the men will be the easier to secure I cannot say; but as to the men I believe that relatively few will be found ready made; they will have to be engaged in an immature stage and developed to maturity here and elsewhere. Of course some fully competent geographers will be brought here, ready at once to undertake research. But it is more probable that the staff will be built up gradually by the engagement and promotion of young men. A practical method to that end is to select a young man of promise and give him opportunity for growth by study and travel, during which he may specialize in one subject or another; then on his return he may be given an appointment for a term of years, and at the end of that term, he may be given a permanent appointment if his work has been such as to justify it. Gradual growth in some such way will I believe lead to better results than can be gained by the wholesale appointment of a full staff, even if that were possible from the financial side of the problem. In the mean time, instruction by visiting lecturers and by professors invited for a year from Europe will add to the attractiveness of whatever regular instruction can be given, especially in the undergraduate department of the University ; but neither visiting lecturers nor temporary professors from abroad can give the solidity and continuity of work that should characterize a properly constituted and truly American Graduate School of Geography. Hence if the proposed staff of nine research professors is established in ten or twenty years, that will be doing well, remarkably well.

THE PROPER STANDARD FOR A GRADUATE SCHOOL OF GEOGRAPHY

The dangers are more serious. They will arise chiefly from the pressure and urgency of students, of undergraduate rank geographically, whose needs, indeed, whose deficiencies, will tend to divert the professors of the Graduate School proper from their primary duty, research, to a secondary duty, teaching. I must here point out an essential difference, between teaching and studying. In secondary schools, the teachers must do a great deal of teaching because the pupils are only just 
learning how to study. In colleges, the teaching by the professors and the studying by the students may about balance each other. In properly constituted graduate schools the properly prepared students should be expected to do most of their study by themselves; the duty of the graduate staff of professors is chiefly to set example and pace by doing their own research work, and to give occasional guidance to students working with them, but not to do set teaching.

Now, the mere announcement that Clark University is going to establish a Graduate School of Geography will attract college graduates to come here. Some such graduates will be properly qualified by their previous studies to enter the Graduate School at once, but many of them will come from colleges where the undergraduate teaching of geography is so imperfectly developed that they will not be sufficiently grounded in the elements to enter upon truly advanced work. What shall be done with such students when they arrive here? Manifestly they should have more undergraduate instruction, but they will not like to be enrolled with undergraduates again. Yet if they are immediately admitted to the Graduate School of Geography, its standard as a school of research will be injuriously lowered.

I therefore suggest that the present graduate department of the University be continued without specification of subjects studied; and that graduates of other colleges on coming here should be enrolled in that graduate department until they have completed the requirements for admission to the Graduate School of Geography.

But even so, the introductory teaching that they will need, as well as the introductory teaching needed by Clark undergraduates who propose to make geography their life work, will demand that a considerable body of undergraduate teaching in geography be offered here; and for that purpose three professors will be called for at the very least. There is danger that the research professors in the Graduate School of Geography will be drawn into this work. Naturally enough, undergraduate geography will be developed here before the Graduate School of Geography is fully established; and with such a beginning it may be difficult to establish a Graduate 
School of the kind I have outlined. The college professors of geography will themselves wish to have some time for original studies; some of them will wish to give graduate instruction. And thus, even if one or two research professors are added, a half-developed Graduate School of Geography may grow up, in which research is only incidental and secondary, and teaching of an undergraduate grade is the larger duty.

The very respectability of such an arrangement is ominous. It will be so good that a better arrangement, a real professional Sehool of Geography may be lost sight of; and yet a mixed school of that sort will be only "another" school of the mixed kind; and being attached to a small university instead of to a large one it will have no particular merits; it will not stand out with a pre-eminence of its own. As I am only a Commencement speaker and not a Trustee, my duty goes no farther than to point out this threatening danger. It will be for others to provide safeguards against it. I may, however, note in passing that, although a number of other universities have already reached the stage of offering geographieal instruction in both their undergraduate and graduate departments, none of them think it worth while to segregate the graduate part of such mixed instruction under so ambitious a name as a Graduate School of Geography ; and I believe that they are quite right in not doing so because they do not propose, for the present at least, to provide opportunity for advanced work in geography so far in excess of that provided in other subjects as to warrant the announcement of a School of Geography. It is here that the opportunity for geography in Clark University is likely to be for a long time unique; because in this University geography is, if I understand the plans of the Trustees correctly, to be given as great pre-eminence over other subjects of graduate study as possible. It cannot reach great pre-eminence immediately, for as I have already pointed out it is not possible immediately to secure a staff of research professors. The unique feature of geographical opportunity at Clark is therefore the aim in view; namely, to establish a real Graduate School of Geography as soon as possible. The recent appointment of a geographer to the presidency of the University is evidence of the seriousness 
with which this aim is regarded by the Trustees. They have my heartiest good wishes for their success, but it is evident that success cannot be reached if the research professors in the Graduate School are distracted from their proper work by the necessity of giving undergraduate instruction.

UNDERGRADUATE PREPARATION FOR GRADUATE WORK

There is a second danger about as serious as the first. Properly qualified members of a properly constituted Graduate School of Geography ought not only to have already acquired a good understanding of fundamental undergraduate courses in geography; they should also have acquired a good understanding of some one or two other subjects allied to those systematic divisions of geography in which they propose to specialize. The requisite undergraduate courses in geography itself should represent several of the chief systematic divisions of geographical science; for example, land and water forms, climatology, human geography, economic geography; and also one or two introductory courses in regional geography, for example, North America and some other continent. These taken together should constitute the equivalent of a whole year's undergraduate work at least. But in addition thereto, a student who proposes to specialize in one or another division of systematic geography should have made good undergraduate progress in some other subject closely allied to that division.

Thus, one who specializes in human geography should have taken several undergraduate courses in the allied subject of history on one hand, or in anthropology and ethnology on the other. A student who proposes to specialize in economic geography should be well prepared in the allied subject of economics; and one who selects plant geography or animal geography for his special subject of preference, should be well grounded in the allied subject of botany or zoology; and so on. These allied subjects should occupy from half a year to a year of undergraduate study. Furthermore, a real facility in reading French and German and, still more important, a trained capacity to write good English should be included 
among the results of undergraduate study. No student, of whatever college he may be a graduate, should be admitted to the Clark Graduate School of Geography if he falls seriously short in any of these undergraduate requirements. He may be admitted, of course to the graduate department of the University, if he holds a bachelor's degree from any reputable collegiate institution; but so long as he has serious deficiencies in the undergraduate preparation for the graduate study of geography, he ought not to be admitted to the Clark Graduate School of Geography, or to any other such graduate school. For in just so far as a member of a professional graduate sehool uses his time there on undergraduate studies, he lowers the standing of the school; and any one who looks on the high standing of his school with pride should be jealous of all influences which tend to lower it.

The seriousness of this danger of unpreparedness and the importance of establishing safeguards against it ought to be manifest to any one who is familiar with the demoralizing influence exerted on a graduate student's work for a higher degree by the necessity of making up undergraduate deficiencies at the same time. Work for a higher degree should occupy a student's whole attention. If in his graduate years he is giving part of his time to undergraduate subjects, which he ought to have studied earlier, he is not only distracted thereby from his proper graduate work, but the graduate work which he does will be weakened by reason of not being based on a completed foundation. In a word, the student members of a professional graduate school ought to be well.trained for the work that they have to do there; as such they constitute a select body of which any institution must be proud.

\section{THE DIFFERENCE BETWEEN STUDYING AND BEING TAUGHT}

You may now understand better than before what was meant by my earlier insistence that teaching should not be a prime duty of the research professors in a true Graduate School of Geography; for the fact that they are not to teach does not imply that they are to have no students. Of course, they are to have students, properly qualified graduate students; and the students are to study; but the professors are 
not to teach in the ordinary sense of the word. The students having reached that stage of their education when they have learned how to study and when they really wish to study, are to study chiefly by themselves on their special subjects. The professors are to propose problems for them, to advise and to guide them in the study of the problems, to hold conferences with them, but not to teach them. And with the conception of a body of professors devoted chiefly to research in the several departments of a single science, and of a body of students devoted chiefly to study in different subdivisions of the same science, you may imagine the atmosphere by which a Graduate School should be enveloped. It is one of the most delightful, most inspiring atmospheres in which human beings can live.

\section{THE PREPARATION OF TEACHERS OF GEOGRAPHY}

A practical question may, however, rise in your minds. If the requirements of a Graduate School of Geography are so high, is it likely that any students will wish to enter it? I can give several very confident answers to that question. In the first place, a candidate for the position of teacher in a secondary school ought not to be encouraged to enter it. $\mathrm{He}$ can acquire during his undergraduate college years as much knowledge of the subjects which he is to teach as he will need; and, moreover, inasmuch as a school teacher should be more interested in the boys and girls that he teaches than in the subjects which the boys and girls are to be taught, it is not necessary for him to carry preparatory studies to the point of becoming engrossed in research. In the second place, a candidate for the position of professor of geography in a college should without question be encouraged to enter such a Graduate School of Geography as I have outlined, and to stay there long enough to earn a master's degree at least, and a doctor's degree if possible. College professors ought to be learned persons; and as a preparatory step toward becoming learned they ought to have breathed an atmosphere of learning for a year or two. To be sure, a candidate for a professorship in a college where the teaching of geography is combined with the teaching of another subject may make the 
other subject his first interest, and may not, therefore, feel justified in carrying his geographical preparation very far. But it is encouraging to see that geography is coming to be recognized in more and more of our colleges as a subject large enough and important enough to occupy the whole of a professor's time. Young men who have the ambition to be professors of geography in colleges of that grade should be urged to take a doctor's degree in geography; and to young men of that sort the Clark Graduate School of Geography should be powerfully attractive, if it is organized on the lines I have indicated.

\section{GEOGRAPHICAL ENGINEERS}

But there is an altogether different group of positions for which young men will be increasingly needed as the affairs of the world, now so disordered, return to a more normal condition, and as, in consequence of that return, international commerce comes to flourish again, particularly those branches of international commerce which have to do with the less known continents of South America, Africa and Asia. At that time, which we may hope will not be too long delayed, many of our larger commercial houses will find, as some of the most enterprising have already found, that they need much more information than is ordinarily available regarding the more distant parts of the world; and they will learn that it is profitable to secure that information from trained experts. In my opinion the experts who can best give that sort of information will be high grade geographers, who have specialized in economic geography as well as in the regional geography of one or another continent.

The Clark Graduate School of Geography ought to make a specialty of training such men: their specialty ought to be called geographical engineering, and those who become proficient in it ought to receive the degree of Geographical Engineer. Needless to add that training of that kind must be based on a broad and firm foundation of undergraduate studies in a well equipped college, and must be extended by continuing those studies in a thoroughgoing professional School of Geography; and the training will need one other element, namely, after the professional study is well advanced, 
a year of studious travel in the continent selected for special attention. For, although the later work of a geographical engineer must be largely of so practical a nature as to satisfy the money-making demands of commerce, the preparation for that work cannot be made by learning definite answers to set questions. The problems that the geographical engineer has to answer will be as a rule so novel, so individual, that his best training for them will be found first in the comprehensive acquisition of all the fundamental knowledge in his specialty, and second in the original study of novel and individual problems in the same specialty, that is, research in economic geography. Hence even for this most practical field of geographical science, experts will be best made ready by close association with older experts who are carrying on researches in the same field. Men who have received high-grade preparation of that kind will be sought for and prized.

\section{THE CLARK SCHOOL A CENTER OF GEOGRAPHICAL ACTIVITY}

Can you not imagine the eagerness and earnestness with which the students in a Graduate School of Geography will pursue their studies? They will be proud of their association with a staff of research professors; they will be devoted to their science and delighted with the opportunity that the School affords of advancing themselves in it; they will be ambitious to become proficient in the science and to apply their proficiency to serious tasks in the actual world. Can you not understand also that the presence of such a Graduate School of Geography in Worcester, with its corps of expert professors, its well developed material equipment, its body of enthusiastic students and its exhilarating scholarly atmosphere, will attract intending and returning travelers to visit it, to stay near it for a time, and to establish more or less formal relations with it? An intending traveler may well spend several months under its influence while making preparations for his journey; a returning traveler may advisedly remain an entire year in its wholesome atmosphere while writing his account of an accomplished journey. Can you not see that the school will become a notable center of geographical activity if its development follow serious professional lines? It will 
inevitably become such a center, and it will thereby exert a greatly needed and most beneficent influence on the cultivation of scientific geography all over our country. That the beginning now made should have some such consummation is my devout wish. When that wish is realized, then wherever geography is seriously spoken of in America, the speaker and his hearers will find themselves thinking spontaneously of the Graduate School of Geography at Clark University. 






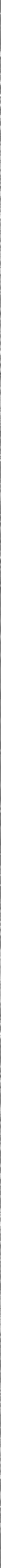




\section{UNIVERS... UE …LL ORNIA LIBRARY BERKELEY}

Return to desk from which borrowed.

This book is DUE on the last date stamped below.

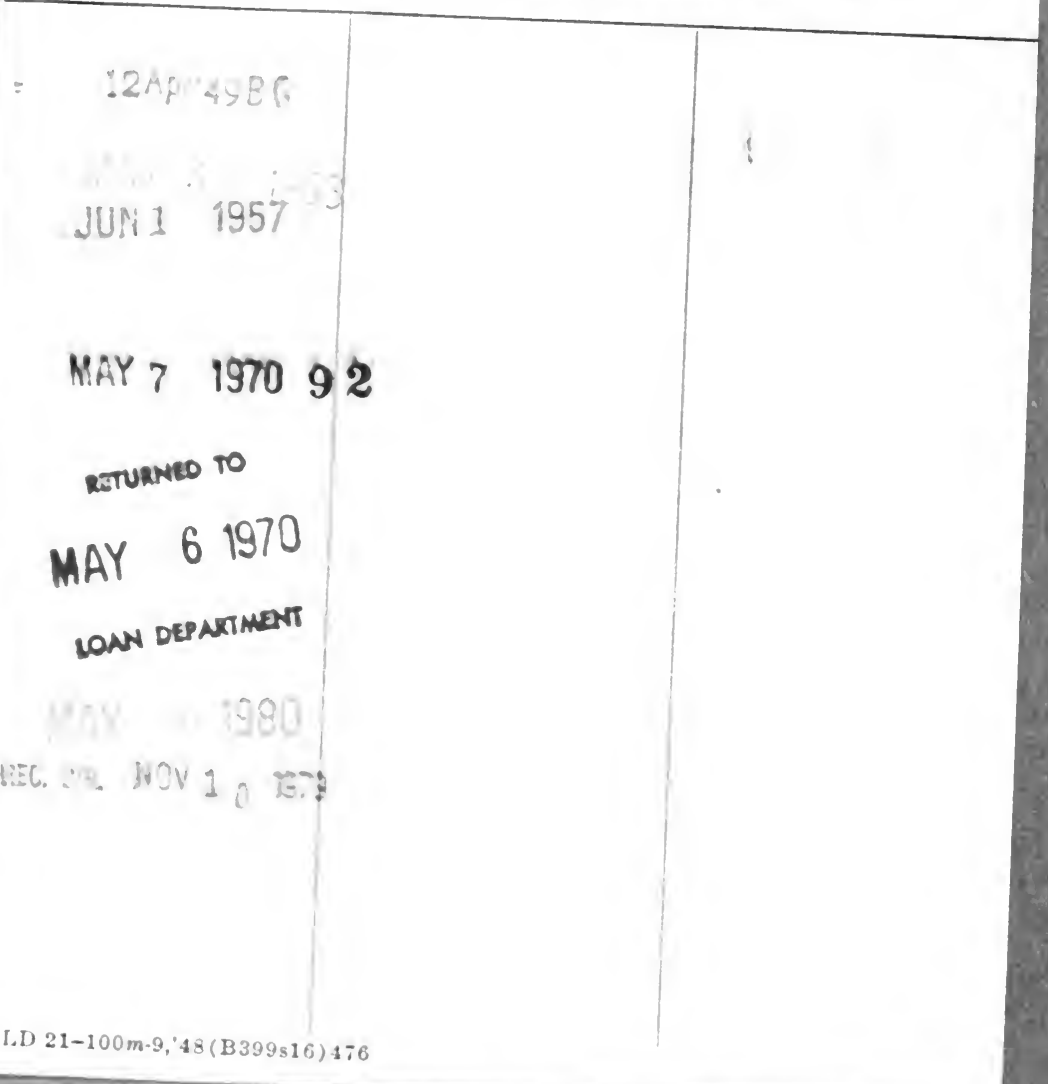




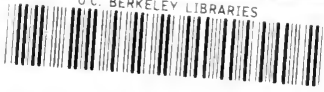

COJl2lib686

\section{(1)}

THE UNIVERSITY OF CALIFORNIA LIBRARY 

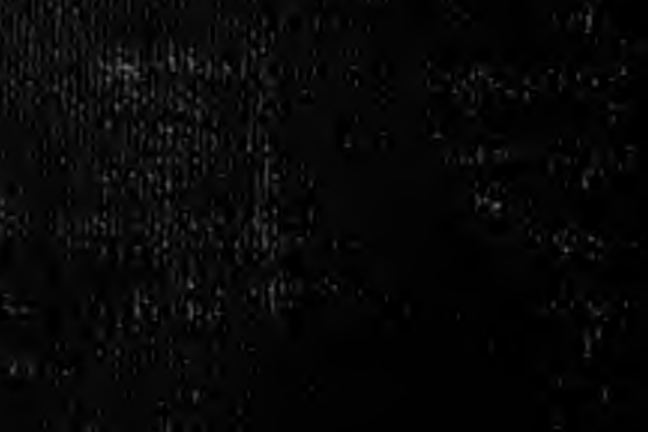